\title{
REDES NEURAIS NA MODELAGEM DE UMA COLUNA DE STRIPPING DE CLORO
}

\author{
F. A. COELHO ${ }^{1}$, F. de O. CARVALHO ${ }^{2}$, J. dos S. SILVA ${ }^{2}$, R. de O. FARIAS ${ }^{2}$ e J. I. H. TAVARES \\ $\mathrm{NETO}^{3}$ \\ ${ }^{1}$ Universidade Estadual de Campinas, Faculdade de Engenharia Química \\ ${ }^{2}$ Universidade Federal de Alagoas, Centro de Tecnologia \\ ${ }^{3}$ Braskem \\ E-mail para contato: filipea_c@hotmail.com
}

\begin{abstract}
RESUMO - Devido a complexidade e ao esforço computacional utilizado para a solução dos modelos fenomenológicos de equipamentos industriais, o uso de redes neurais artificiais, na modelagem empírica de processos se apresenta como uma boa alternativa, uma vez que resolve o problema da complexidade da modelagem fenomenológica por meio de modelos mais simples sem a necessidade do equacionamento dos balanços de massa e energia. As redes neurais artificiais têm a capacidade de "aprender" o comportamento do processo ou equipamento através de um histórico de dados do seu funcionamento. $\mathrm{O}$ presente trabalho mostrou a viabilidade de se utilizar redes neurais artificiais na modelagem de uma coluna de dessorção de cloro de uma indústria de clorosoda do estado de Alagoas. A rede neural utilizada foi uma MLP (Multilayer Perceptron) e a validação foi feita por engenheiros da unidade industrial e por modelos fenomenológicos do equipamento previamente conhecidos.
\end{abstract}

\section{INTRODUÇÃO}

O cloro é usado direta e indiretamente na produção de produtos químicos orgânicos e inorgânicos. Uma das maiores aplicações do cloro é na produção de PVC (cloreto de polivinila), via EDC (dicloroetileno) e MVC (cloreto de vinila). Em condições atmosféricas, o cloro se apresenta como um gás e nesta condição é perigoso e altamente corrosivo. Em solução aquosa, espécies cloradas podem ocorrer devido a hidrólise do $\mathrm{Cl}_{2}$, tais como ácido hipocloroso (HClO), mostrado na Equação 1 (Black \& Veatch, 2010). A constante de equilíbrio da reação é mostrada na Equação 2.

$$
\begin{aligned}
& \mathrm{Cl}_{2}+\mathrm{H}_{2} \mathrm{O} \leftrightarrow \mathrm{HClO}+\mathrm{H}^{+}+\mathrm{Cl}^{-} \\
& \log K_{d}=-\frac{982798}{T^{2}}+\frac{5485,7}{T}-10,7484
\end{aligned}
$$

Ao observar a Equação 2, nota-se que a constante de equilíbrio diminui com o aumento da temperatura, indicando que a reação é deslocada no sentido de formar $\mathrm{Cl}_{2}$ em fase aquosa. Além disso, a concentração de $\mathrm{Cl}_{2}$ em fase aquosa, como ocorre com diversos gases, diminui com o aumento da temperatura. 


\section{9 a 22 de outubro de 2014 \\ Florianópolis/SC}

Dessa maneira, em processos industriais com efluentes clorados, o $\mathrm{Cl}_{2}$ pode ser removido da água elevando-se a temperatura, tipicamente até $100^{\circ} \mathrm{C}$. Entretanto, isso não removeria o cloro presente na forma de outras espécies cloradas, como o $\mathrm{HClO}$, por exemplo. Para resolver esse problema, $\mathrm{HCl}$ pode ser adicionado à corrente, visando deslocar a reação de equilíbrio e consumir o $\mathrm{HClO}$, removendo por completo o cloro presente na fase aquosa. Equipamentos que permitam contato de fases, como colunas de stripping, foco deste trabalho, podem então ser usados para promover a separação do cloro e de compostos clorados.

O tratamento de efluentes por meio de stripping é um processo de transferência de massa líquido-vapor no qual componentes voláteis do meio líquido, por ação de um fluxo de ar ou vapor em contracorrente, são transferidos para o meio gasoso. Os processos de stripping são conduzidos principalmente em colunas com pratos ou recheios e menos frequentemente em colunas de pulverização, colunas de borbulhamento e em contactores centrífugos. Numa coluna com recheios, uma corrente líquida escoa por ação da gravidade, na forma de filme ou gotas, sobre uma ou mais seções do recheio. $\mathrm{O}$ vapor escoa de forma ascendente, entrando em contato com o líquido na superfície do recheio.

Em escala industrial, a automação e controle de uma coluna de stripping não é uma tarefa trivial, uma vez que a variável controlada é a concentração de cloro na saída do equipamento e a medição automática em linha desta variável é economicamente inviável. Desta forma, o uso de analisadores virtuais pode ser vantajoso. Segundo Fortuna et al (2007), um analisador virtual é um modelo de processo dedicado à estimação de variáveis, e apresenta algumas vantagens tais como: baixo custo, operação em paralelo com sensores reais, facilidade de implementação em hardwares (microcontroladores), e permitem estimação de dados em tempo real.

Neste trabalho é realizada a modelagem e simulação de uma colona de stripping real utilizando o simulador Aspen Plus Dynamics para, a partir de dados simulados, investigar a utilização da técnica de redes neurais como sensores virtuais na inferência do teor de cloro.

\section{REDES NEURAIS}

A Rede Neural Artificial (RNA) é um modelo matemático que tenta imitar em sua estrutura a complexa rede de neurônios do cérebro humano, refletindo no comportamento de uma máquina que aprende em situações de causa-efeito. A vantagem das redes neurais em comparação com a modelagem tradicional, via balanços de massa e energia, é o completo desconhecimento da natureza fenomenológica do processo que se quer modelar, necessitando-se apenas de um histórico de dados das principais variáveis do problema. Processos altamente não-lineares ou cujos fenômenos são desconhecidos podem ser modelados então com redes neurais.

Em uma RNA, o armazenamento da informação é feito em nodos (neurônios), que são organizados na forma de uma rede. Nessa rede, o sinal de entrada de um neurônio é a ponderação de vários sinais oriundos de diversos outros neurônios somados a um bias (que serve para aumentar os graus de liberdade do neurônio). $\mathrm{O}$ sinal resultante é processado por uma função de ativação e dependendo da intensidade, este é enviado ou não ao neurônio seguinte, reproduzindo o estado excitado ou inibido de um neurônio biológico.

Um tipo comum de rede neural artificial é a do tipo MLP (Multilayer Perceptron), que é bastante utilizada como aproximadora de funções multivariáveis. As redes MLP apresentam no mínimo 3 camadas, 


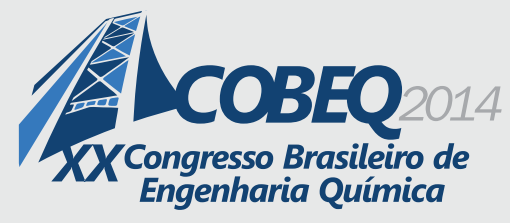

19 a 22 de outubro de 2014
Florianópolis/SC

com pelo menos um neurônio cada: camada de entrada, onde os neurônios representam as variáveis de entrada (variáveis independentes) que as distribuem para a(s) camada(s) escondida(s); camada(s) escondida(s), onde os neurônios realizam o processamento, através de regras de propagação e funções de ativação e camada de saída, onde os neurônios representam as variáveis de saída (respostas da rede). A definição do número de camadas e de neurônios em cada camada intermediária assim como as funções de ativação para cada camada é definido a partir de um método de otimização.

Na Figura 1 estão representados os principais elementos de uma "típica" rede neural MLP, onde $x$ e $y$ representam entrada e saída, respectivamente; $w$ representa os pesos e $f(x)$, a função de ativação (logística) (Carvalho et al 2010a).
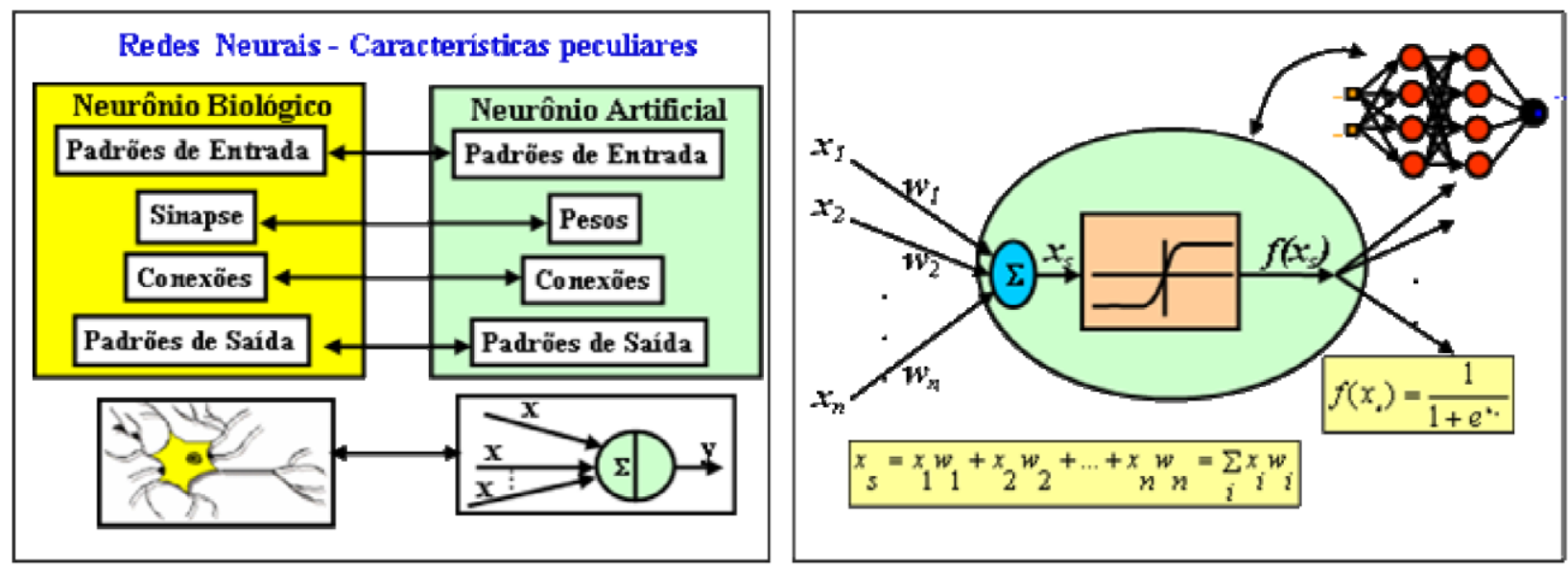

Figura 1 - Rede neural "típica” e comparação entre um neurônio biológico e artificial.

Para a obtenção dos pesos das conexões, é utilizado um procedimento conhecido como treinamento ou aprendizado supervisionado de uma RNA, que através de uma otimização minimiza uma função erro dada pela diferença entre a variável de saída calculada pela rede e um valor da variável de saída conhecido. Este processo de aprendizado ocorre através dos ajustes sucessivos dos pesos e, em alguns algoritmos, por meio dos resíduos de ativação, de forma a se obter dados de saída o mais próximo possível dos desejados (Carvalho et al 2010a).

Um algoritmo utilizado para o treinamento de RNA atualmente é o algoritmo de Levenberg-Marquart, desenvolvido para se obter uma rápida velocidade de treinamento (Carvalho et al 2010b). O Toolbox de Redes Neurais do pacote computacional Matlab 7.0 foi utilizado nos cálculos descritos na sequiência deste trabalho.

As redes neurais podem ser utilizadas, então, para representar processos complexos como a inferência da concentração de $\mathrm{Cl}_{2}$ no processo de stripping de cloro em uma coluna com recheio, ao invés de utilizar um sistema de equações diferenciais e um sistema de complexas equações termodinâmicas para eletrólitos. 


\section{METODOLOGIA}

A coluna modelada neste trabalho é uma coluna real e consiste de uma coluna de stripping com recheios do tipo Intalox de 1" de termoplástico distribuída em duas seções de recheio com $3 \mathrm{~m}$ cada uma. A coluna opera à pressões próximas da atmosférica. A corrente de água (saturada com cloro) a ser tratada entra na coluna a uma temperatura de $90^{\circ} \mathrm{C}$ e uma vazão de $20 \mathrm{~m}^{3} / \mathrm{h}$. Essa corrente aproveita calor oriundo da corrente de fundo da coluna através de um trocador de calor, mas essa integração não foi modelada uma vez que apenas a temperatura final de entrada é de interesse para o modelo.

Para remover o cloro, a coluna utiliza vapor saturado um pouco acima da pressão atmosférica com uma vazão nominal de $1000 \mathrm{~kg} / \mathrm{h}$. Essa corrente de vapor aquece a corrente de água até $100^{\circ} \mathrm{C}$, temperatura na qual o cloro é removido praticamente por completo. Entretanto, o cloro pode permanecer na corrente na forma de outros compostos clorados, como o HClO. Para evitar isso, a corrente de entrada é misturada com uma corrente de $\mathrm{HCl} 25 \% \mathrm{~m} / \mathrm{m}$ e um controle de razão mantém a vazão a uma razão de 0,02 entre a vazão de $\mathrm{HCl}$ e a de água.

A aquisição dos dados de treinamento da rede neural foi obtida através de um modelo em Aspen Dynamics validado por engenheiros da planta, em vista da dificuldade de realização de ensaios na planta real.

A coluna foi simulada com o modelo de equilíbrio RadFrac, composto por 3 estágios de equilíbrio referentes à duas sessões de recheios e ao fundo da coluna. A pressão na coluna real é aproximadamente 1atm, assim, a pressão foi fixada no tambor de condensação em 1atm e a queda de pressão ao longo da coluna, decorrente do recheio, foi modelada pela metodologia de Stichlmair. Para os coeficientes do fator de atrito da equação de Stichlmair foram usados os valores fornecidos por padrão no Aspen Plus para selas Intalox de plástico.

Foram mantidos dois controladores na coluna: um controlador de pressão, manipulando a vazão de saída de vapor no topo e um controlador de nível no fundo da coluna, manipulando a vazão de saída no fundo. Estes controladores foram mantidos com a sintonia padrão do Aspen Dynamics.

Devido à presença de eletrólitos na água, o modelo termodinâmico ELECNRTL foi considerado. O sistema de reações consideradas está mostrada na Equação 3.

$$
\begin{aligned}
& \mathrm{H}_{2} \mathrm{O} \leftrightarrow \mathrm{H}^{+}+\mathrm{OH}^{-} \\
& \mathrm{HCl} \leftrightarrow \mathrm{H}^{+}+\mathrm{Cl}^{-} \\
& \mathrm{Cl}_{2}+\mathrm{H}_{2} \mathrm{O} \leftrightarrow \mathrm{HClO}+\mathrm{H}^{+}+\mathrm{Cl}^{-} \\
& \mathrm{HClO} \leftrightarrow \mathrm{ClO}^{-}+\mathrm{H}^{+}
\end{aligned}
$$

A rede neural utilizada para a inferência da composição de cloro da corrente de fundo da coluna foi uma MLP com uma camada intermediária composta por 15 neurônios com funções de ativação tangente hiperbólica. A camada de saída utilizou função linear. O algoritmo de treinamento foi o Levenberg-Marquardt e o treinamento utilizou $20 \%$ dos dados para validação, para evitar overfitting. Os dados foram normalizados com uma função logarítmica visto que a diferença da ordem de grandeza da concentração entre o maior e o menor valor é de 106 PPM. Para testar a rede foram usados um conjunto de dados referentes à $15 \mathrm{~h}$ de 
simulação, composto por 2000 amostras. A rede foi construída e treinada no software Matlab.

O conjunto de dados foi constituído das seguintes variáveis: temperatura e vazão da corrente de entrada, vazão de vapor, vazão de $\mathrm{HCl}$ e temperatura de fundo. A variável de saída foi a concentração de $\mathrm{Cl}_{2} \mathrm{em} \mathrm{PPM}$. Adicionalmente, também foram usadas como variáveis de entrada todas as variáveis e a concentração de $\mathrm{Cl}_{2}$ em um instante anterior de tempo.

Para gerar os dados para a rede neural, foi utilizado um sinal multi-nível (MLPRS), que testa o sistema em diferentes pontos de operação permitindo identificar comportamentos não-lineares do sistema. Trabalhos na literatura mostram a eficácia do sinal na identificação como o trabalho de Jelenka et al (2000) utilizando um sinal MLPRS para modelar a dinâmica de um tanque para controle de $\mathrm{pH}$.

O sinal MLPRS foi implementado por meio do bloco PRBS do Aspen Dynamics com amplitude variável para perturbar algumas das variáveis de entrada, uma por vez, com período de 30 minutos, período este observado como médio para o sistema restabelecer o estado estacionário. Foram gerados 9000 amostras com tempo de amostragem de $0,01 \mathrm{~h}$, durante um tempo de simulação de $30 \mathrm{~h}$ para cada variável perturbada. A amplitude de cada variável foi estabelecida de acordo com a amplitude usual das respectivas variáveis do processo. A Figura 2 resume as perturbações efetuadas em cada uma das variáveis. A Tabela 2 resume a variação utilizada no sinal PRBS.

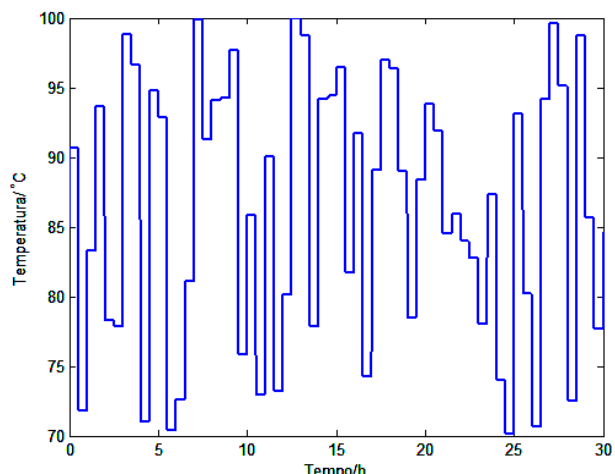

(a)

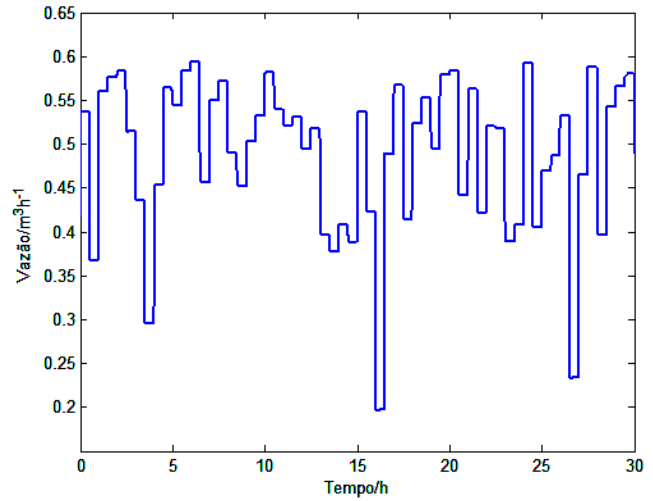

(c)

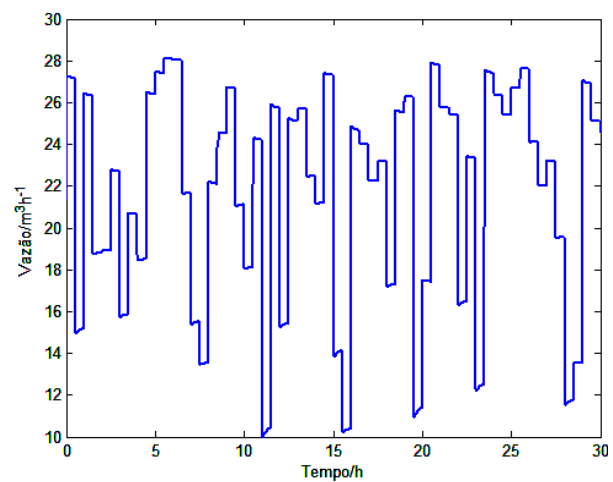

(b)

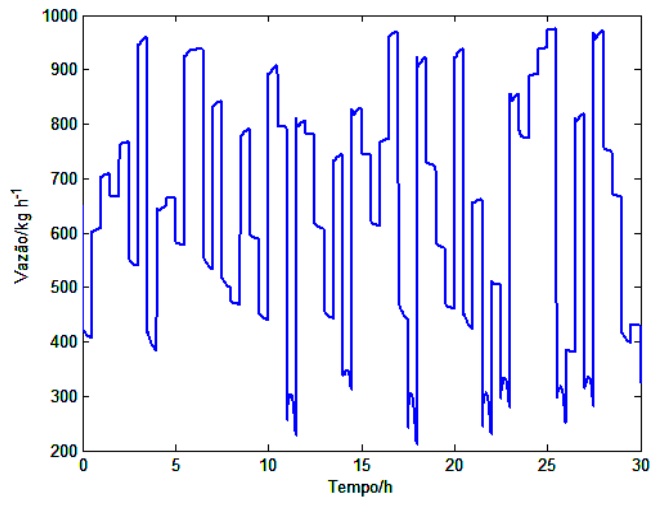

(d)

Figura 2 - Perturbações com sinal PRBS: (a) temperatura da corrente de água e (b) vazão da corrente de água, (c) vazão de $\mathrm{HCl} \mathrm{e} \mathrm{(d)} \mathrm{vazão} \mathrm{de} \mathrm{vapor.}$ 
Tabela 2 - Variáveis perturbadas pelo sinal PRBS e faixa de atuação.

\begin{tabular}{|c|c|}
\hline Variável & Faixa \\
\hline $\begin{array}{c}\text { Temperatura de } \\
\text { entrada da água }\end{array}$ & $70-100^{\circ} \mathrm{C}$ \\
\hline Vazão de vapor & $100-1100 \mathrm{~kg} / \mathrm{h}$ \\
\hline $\begin{array}{c}\text { Vazão de entrada da } \\
\text { água }\end{array}$ & $10-30 \mathrm{~m}^{3} / \mathrm{h}$ \\
\hline Vazão de $\mathrm{HCl}$ & $0-0,5 \mathrm{~m}^{3} / \mathrm{h}$ \\
\hline
\end{tabular}

As concentrações resultantes das perturbações com sinal PRBS são apresentadas na Figura 3. Nota-se pela ordem de grandeza da concentração que a vazão de vapor é sem dúvida a variável crítica do processo, seguida da temperatura de entrada da água na coluna, vazão de $\mathrm{HCl}$ e vazão de água. O resultado para a perturbação na vazão de água mostra que a vazão nominal de $1000 \mathrm{~kg} / \mathrm{h}$ de vapor é suficiente lidar com oscilações nesta variável, mostrando a robustez da operação.

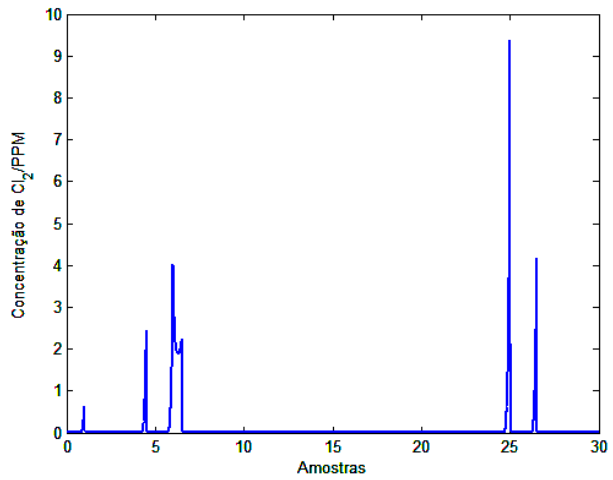

(a)

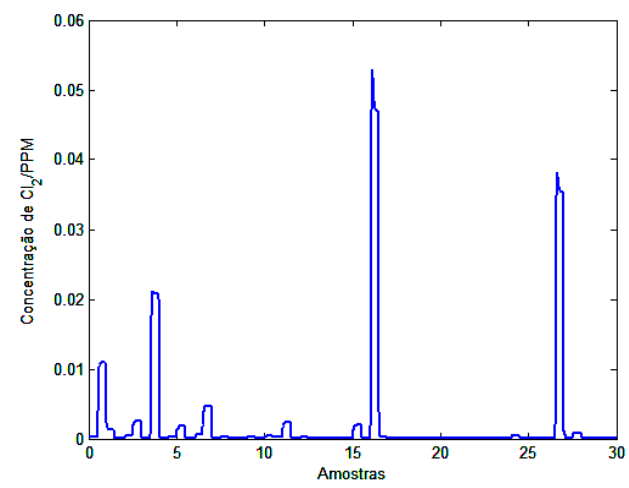

(c)

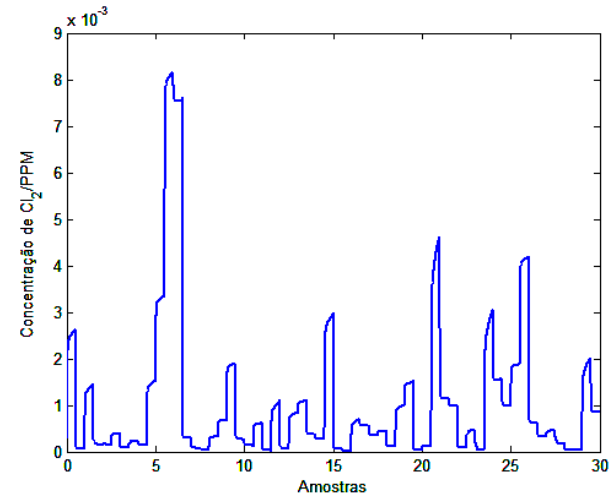

(b)

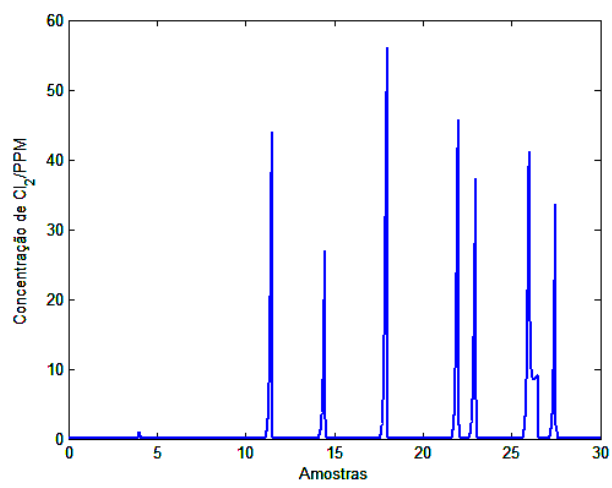

(d)

Figura 3 - Concentração de $\mathrm{Cl}_{2} \mathrm{em}$ resposta às perturbações: (a) temperatura da corrente de água e (b) vazão da corrente de água, (c) vazão de $\mathrm{HCl}$ e (d) vazão de vapor.

A Figura 4 mostra os resultados da regressão dos dados simulados pela rede e os dados do Aspen, no treinamento e na validação. Observa-se em ambas as figura um ajuste com R > 0,9999. Dado que o resultado 
da validação se mostrou satisfatório e em ambos os resultados a reta de regressão se apresentou muito próximo de $\mathrm{Y}=(1) \mathrm{T}+0$, podendo-se dizer, então, que não houve overfitting.

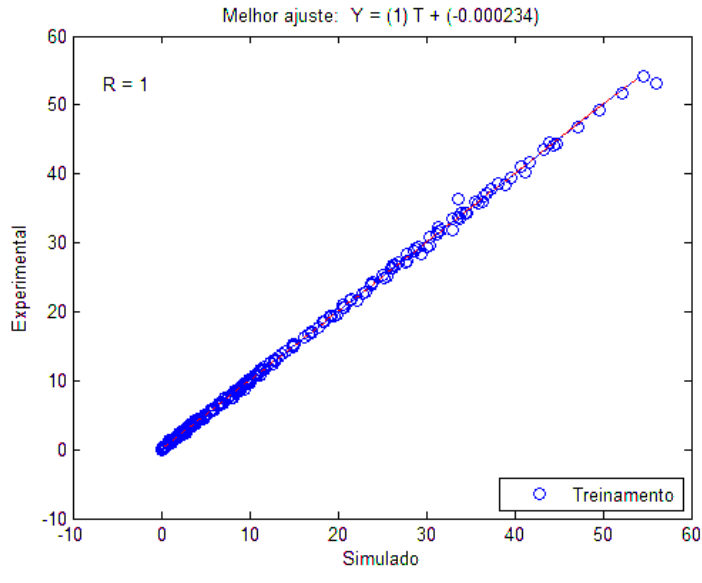

(a)

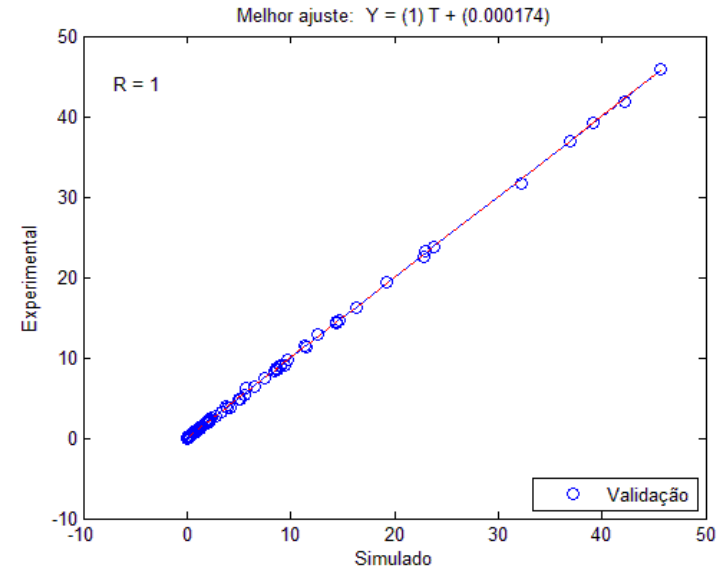

(b)

Figura 4 - Regressão dos dados de (a) treinamento e (b) validação.

A Figura 5a mostra a regressão para os dados de teste. Nota-se também aqui um alto valor para o coeficiente de regressão, com $\mathrm{R}>0,99$, indicando que a rede neural possui uma boa capacidade de generalização da concentração de $\mathrm{Cl}_{2}$ no fundo da coluna. A Figura 5 b ilustra a comparação entre as concentrações apresentadas pelo Aspen e os resultados simulados com a rede neural.

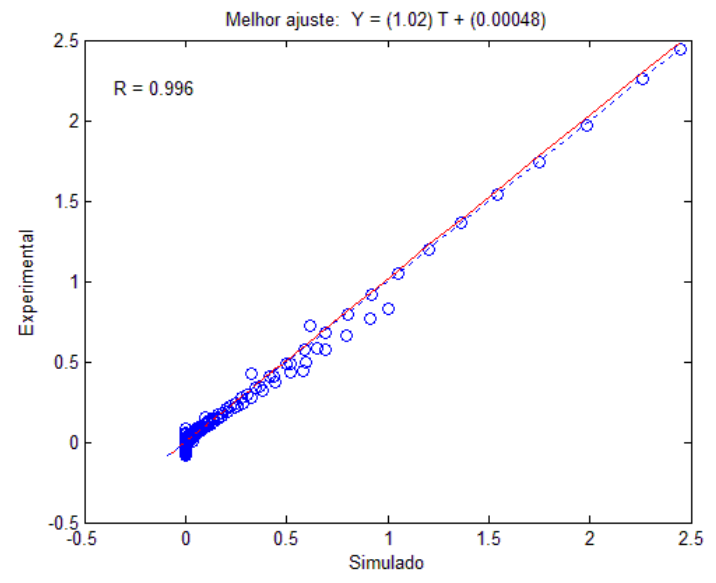

(a)

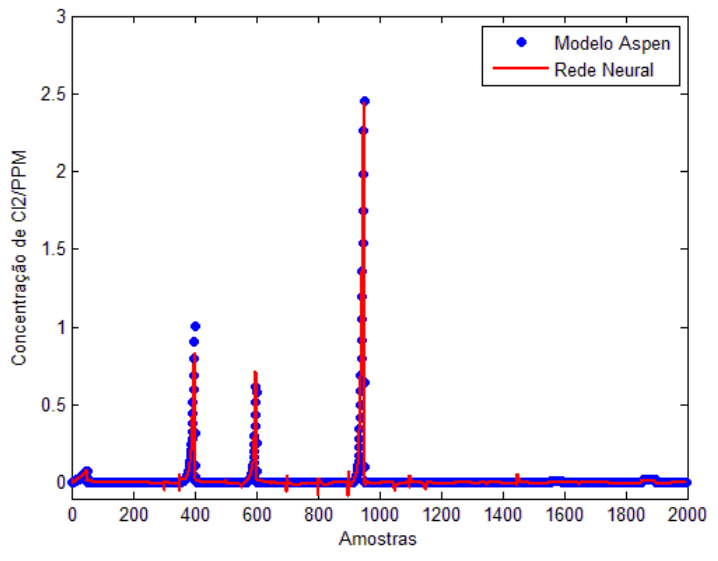

(b)

Figura 5 - Regressão dos dados de teste.

Em grande parte do conjunto de amostras, a rede neural foi capaz de aproximar a ordem de grandeza da concentração e inferir os picos de concentração. Isso é uma característica importante, visto que é exatamente em situações atípicas de processo onde o conhecimento em tempo real da concentração pode ser um fator decisivo na tomada de decisões sobre o reprocessamento da água ou a liberação para o reuso no processo, ao contrário da atual metodologia que necessita de uma análise laboratorial e poderia deixar o engenheiro na posição conservadora de reprocessar a água. 


\section{CONCLUSÕES}

O presente trabalho mostrou a modelagem de uma coluna de stripping visando o monitoramento da qualidade da água tratada em tempo real através de um analisador virtual. Para isso, foi utilizada uma rede neural do tipo MLP como analisador virtual com dados adquiridos de um modelo no software Aspen validado por engenheiros de uma planta real.

Observou-se que a vazão de vapor é a variável mais crítica do processo, influenciando fortemente na concentração de fundo, com potencial para tirar a concentração de fundo de especificação. Os resultados para a rede neural mostraram um ajuste bom com alto coeficiente de regressão, demonstrando a eficácia da abordagem neural na modelagem do processo. $\mathrm{O}$ modelo neural foi capaz de inferir picos de concentração no conjunto de teste, indicando que ele pode ser utilizado como importante ferramenta de tomada de decisões em situações atípicas de processo.

Dado que o modelo neural é um modelo empírico de rápida execução, além da aplicação no monitoramento em tempo real da qualidade da água para o reuso, ele pode ser utilizado em estratégias de controle avançado da coluna, como controle preditivo baseado em modelos, ao manipular a vazão de vapor para controlar a temperatura de fundo e manter o set-point da concentração de $\mathrm{Cl}_{2}$.

\section{REFERÊNCIAS}

Black \& Veatch Corporation. White's handbook of chlorination and alternative disinfectants. $5^{\mathrm{a}}$ edição, 2010.

Carvalho, F.O.; Garcia, C. A. B.; Garcia, H. L.; Coelho, F. A.; Wanderley, H. S.; Santos, R.R.C.; Cavalcanti. J.R.A. Sistemas inteligentes (Redes Neurais) e Estatística Multivariada (PCA) Aplicados a Qualidade da Água. XVIII Simpósio Brasileiro de Recursos Hídricos, 2010a.

Carvalho, F. O.; Coelho, F. A.; Silva, A. N.; Garcia,H. L.; Silva, V. L.; Garcia, C. A. B. Redes Neurais e Estatística Multivariada na Qualidade da Água. Maceió, Brasil, 2010b.

Fortuna, L.; Graziani, S.; Rizzo, A.; Xibilia, M.G. Soft sensors for monitoring and control of industrial processes. Springer, 2007.

Jelenka, B.; Svkovic-Stevanovic; Seider, V.D.; Ungar, L.H. A fuzzy logic controller for pH control of a chemical strirred tank. Chem.Ind., v. 54, p. 384-388, 2000. 